\title{
Novel Yersinia pestis Toxin Resembles Bacillus anthracis Edema Factor: Study of Activity and Structural Modeling
}

V.L. Motin, E. Garcia, D. Barsky, A. Zemla

February 5, 2003

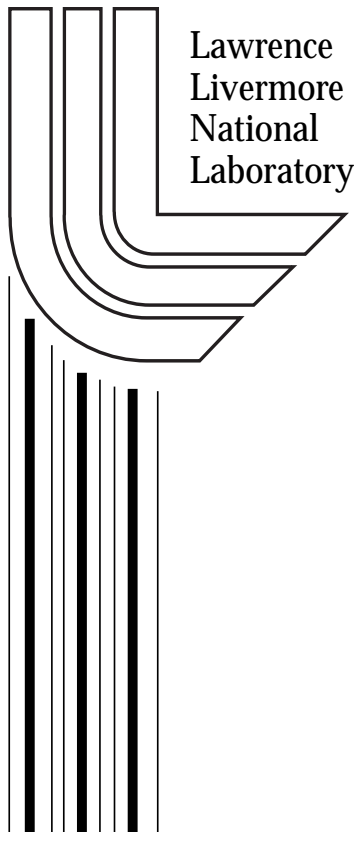




\section{DISCLAIMER}

This document was prepared as an account of work sponsored by an agency of the United States Government. Neither the United States Government nor the University of California nor any of their employees, makes any warranty, express or implied, or assumes any legal liability or responsibility for the accuracy, completeness, or usefulness of any information, apparatus, product, or process disclosed, or represents that its use would not infringe privately owned rights. Reference herein to any specific commercial product, process, or service by trade name, trademark, manufacturer, or otherwise, does not necessarily constitute or imply its endorsement, recommendation, or favoring by the United States Government or the University of California. The views and opinions of authors expressed herein do not necessarily state or reflect those of the United States Government or the University of California, and shall not be used for advertising or product endorsement purposes.

This work was performed under the auspices of the U. S. Department of Energy by the University of California, Lawrence Livermore National Laboratory under Contract No. W-7405-Eng-48.

This report has been reproduced directly from the best available copy.

Available electronically at http://www.doc.gov/bridge

Available for a processing fee to U.S. Department of Energy

And its contractors in paper from

U.S. Department of Energy

Office of Scientific and Technical Information

P.O. Box 62

Oak Ridge, TN 37831-0062

Telephone: (865) 576-8401

Facsimile: (865) 576-5728

E-mail: reports@adonis.osti.gov

Available for the sale to the public from

U.S. Department of Commerce

National Technical Information Service

5285 Port Royal Road

Springfield, VA 22161

Telephone: (800) 553-6847

Facsimile: (703) 605-6900

E-mail: orders@ntis.fedworld.gov

Online ordering: http://www.ntis.gov/ordering.htm

OR

Lawrence Livermore National Laboratory

Technical Information Department's Digital Library

http://www.llnl.gov/tid/Library.html 
UCRL-ID-151371

\section{"Novel Yersinia pestis Toxin That Resembles Bacillus anthracis Edema Factor: Study of Activity and Structural Modeling"}

PI: Vladimir L. Motin, Biology and Biotechnology Research Program, L-452, x2-4740

Co-Investigators (BBRP): Emilio Garcia, Daniel Barsky, Adam Zemla

Final Report for LDRD Project 02-ERD-050

\section{Background}

Plague has had a devastating effect in human history. Even though this microorganism does not represent a public health threat in developed countries, this agent is considered to be a primary choice for both biowarfare and terrorist attack. The current dogma regarding $Y$. pestis pathogenesis predicts that this microorganism does not possess any potent toxin that significantly contributes to its virulence. In general, the acute nature of the plague is poorly understood, but it has been suggested that the death of infected mammals occurs due to massive growth of the microbe in the visceral organs followed by high bacteremia. The only toxin described so far for $Y$. pestis is the so-called murine toxin that represents a phospholipase D class of enzymes, and contributes to the colonization of the midgut of the flea (transmission vector for $Y$. pestis); nontheless, deletion of the murine toxin has no effect on the course of the plague infection as has been shown using an animal model. The complete genome sequence of Yersinia pestis (strain CO92), the causative agent of bubonic and pneumonic plague, has been recently deposited in GenBank by the Sanger Centre (UK). Our analysis of this genome (unpublished observations) revealed that the chromosome of the plague microbe contains a gene that resembles an edema factor (EF) of Bacillus anthracis (one of the two major anthrax toxins); however, this putative function was missed by the annotation performed at the Sanger Centre.

In contrast to the case of $Y$. pestis, toxins are the major reason for the high pathogenic properties of Bacillus anthracis, another agent that has recently brought a strong attention due to bioterrorism activity that has taken place on American soil. The two binary toxins of B. anthracis, lethal toxin (LF) and edema toxin (EF), are located on a naturally occurring plasmid and are considered to be the primary virulence factors of this microorganism. Both of these toxins have been the subject of intensive studies for the past decade leading to the unraveling of their mechanism of action. The edema toxin has been purified and shown to be a potent adenylate cyclase. The enzymes of this class use ATP as a substrate to produce cAMP, the cyclic nucleotide that is considered to be one of the most important global regulators of cell functioning. In contrast to the intracellular adenylate cyclases that perform a housekeeping role in both prokaryotes and eucaryotes, the toxic adenylate cyclase such as produced by $B$. anthracis is excreted out of microbial cell and triggers the response in the infected host (disrupting intracellular signaling pathways). The EF exotoxin from $B$. anthracis contributes significantly to both 
cutaneous and systemic anthrax. It has already been established how to make a fully active recombinant EF toxin, the protein domains are mapped, and the manipulation procedure with this enzyme in vitro is well determined. We anticipate that most of the procedures described for the work with EF toxin from $B$. anthracis could be applied to study a putative homologous toxin of $Y$. pestis.

Homology modeling of proteins is growing compentency at LLNL, with several researchers actively involved in both its development (02-LW-003) and its world-wide assessment (NIH grant to K. Fidelis). The levels of homology between the catalytic domains of $B$. anthracis EF toxin and the $Y$. pestis putative toxin are about $40 \%$, allowing accurate homology modeling.

\section{Purpose}

The goal of this project was to begin both experimental and computational studies of the novel plague toxin to establish its biological properties and create its $3 \mathrm{D}$ - model.

\section{$\underline{\text { Activities }}$}

The project was divided into two parts. I. Experimental. This part was devoted to determine distribution of the genes encoding novel plague toxin among different isolates of $Y$. pestis. If the EF-like activity is important for $Y$. pestis pathogenicity, it is anticipated that all highly virulent strains will contain the toxin genes. Also, we proposed to initiate research to investigate the functionality of the novel $Y$. pestis toxin that we hypothesize is likely to significantly contribute to the virulence of this dangerous microbe. This research design consisted of amplification, cloning and expression in E.coli the toxin genes followed by affinity purification of the recombinant protein that can be further used for testing of enzymatic activity. II. Computational. The structural modeling of the putative EF of $Y$. pestis was based on multiple sequence alignments, secondary structure predictions, and comparison with 3D models of the EF of $B$. anthracis. The X-ray structure of the last has been recently published [Nature. 2002. 415(Jan):396-402]. The final model was selected after detailed analysis to determine if the structure is consistent with the biological function.

\section{Technical Outcome and Accomplishments}

Investigating a distribution of the putative EF gene among different $Y$. pestis strains. Two primer pairs specific for the plague putative toxin genes were constructed and used in PCR reactions to probe the collection of $Y$. pestis strains of different geographical origins, distinct virulence, year of isolation, etc. The testing was done on the same collection of more than 100 DNAs that was recently studied by IS 100 genomic fingerprinting [Motin et.al. J. Bacteriol. 2002. 184(Feb.):1019-1027]. We found that all Y.pestis strains tested (except two isolates) contained the toxin genes. Both toxin-negative strains originated in Vietnam and had identical IS100-type (O2b). Chromosomal mapping of both toxinnegative isolates showed deletion not only of the toxin gene but the deletion also extended to its neighboring region (Fig. 1). The impact of such large deletion of $22 \mathrm{~kb}$ on the virulence of the plague microbe is unknown and should be further investigated. In 
addition, we found that the domains (domain A and domain B) of the putative toxin on the chromosome of $Y$. pestis $\mathrm{CO} 92$ were localized within two subsequent open reading frames (ORFs) (Fig. 1). Such physical separation of the two parts of the toxin was conservative among other 22 plague isolates tested by us. This fact was verified by actual sequencing of the junction region between two ORFs of the toxin in all $22 \mathrm{Y}$. pestis strains.

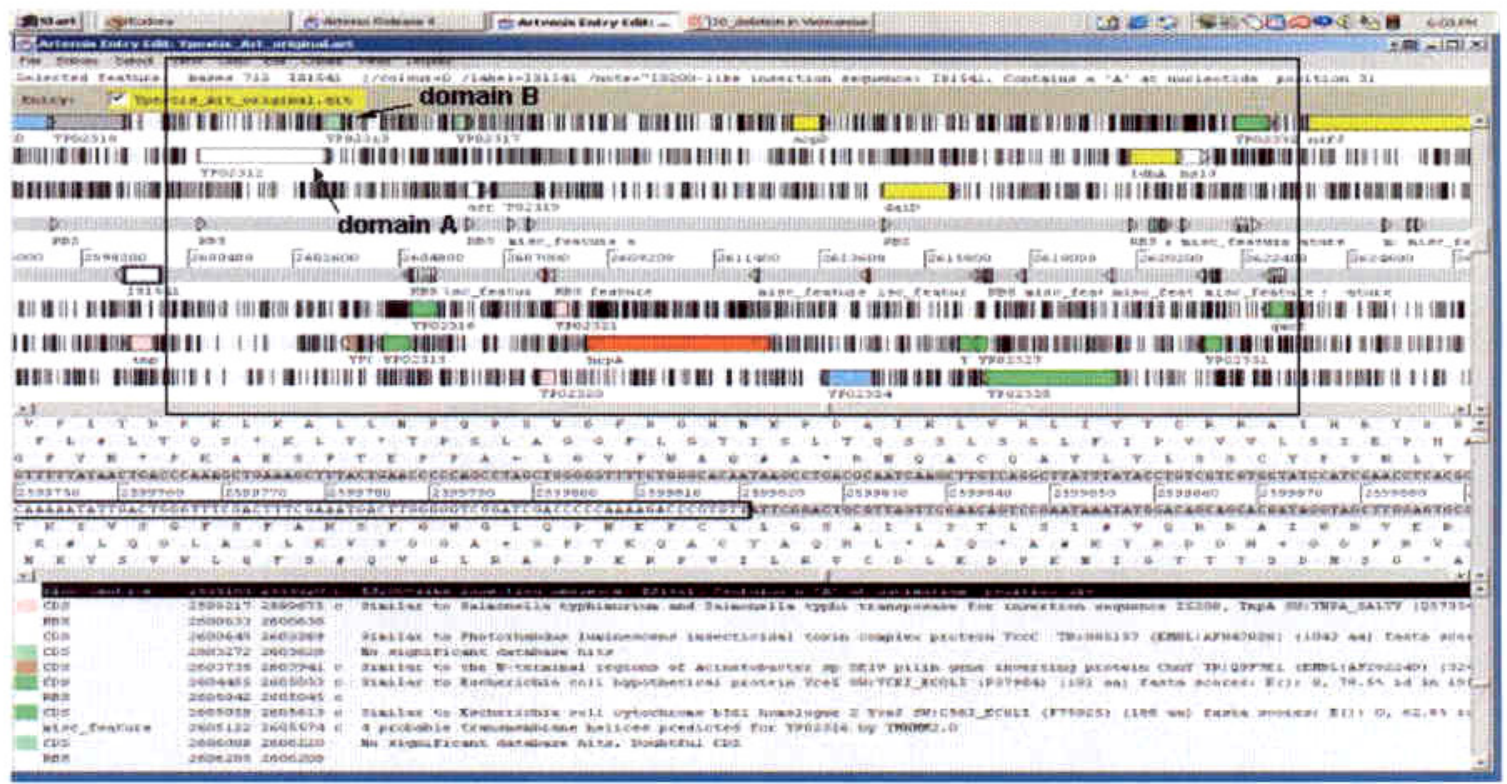

Fig. 1. The map of the region of $Y$. pestis chromosome (strain c092) containing the putative toxin genes. The toxin domain A is located at the C-terminal part of the YPO2312 which is separated from domain B (YPO2313). A large deletion of $22 \mathbf{~ k b}$ found in two toxinnegative isolates from Vietnam is framed.

Cloning and expression of putative $Y$. pestis toxin. The area encoding for the toxin domains A and B was amplified from the chromosome of CO92 strain. The primers for PCR reaction were designed based on sequences presented at GenBank (accession no. AL590842) and contained sites for restriction endonucleases such as EcoRI and XhoI. The sequence of each domain was cloned separately in commercial vector pGEX-4T-2 (Amersham-Pharmacia, $\mathrm{NJ}$ ) to form in frame fusion with Gluthatione S-transferase gene (GST). The sequence of cloned toxin genes was further verified. Each of GST-fusion constructs (Fig. 2A) was transformed into E.coli host to allow the expression of recombinat protein after induction with IPTG for 3-4 hours. The cells then were harvested and immediately lysed in PAGE- sample buffer (whole-cell extracts). The immmunoblot with monoclonal anti-GST antibodies (Pierce, IL) confirmed that both domains of the toxin are expressed as hybrid peptides with GST (Fig. 2B).

Purification of recombinant toxin. The GST- fusions expressed in E. coli were subject to purification using standard procedure described in the manual for pGEX-4T construct 
system. The cells lysates were applied on Glutathione Sepharose 4B column (Pierce) and eluted with reduced glutathione (standard affinity chromatography samples). However, the immunoblot revealed that only $\sim 5 \%$ of GST- toxin domain fusions could be purified using such procedure. The vast majority of the recombinant proteins remained insoluble and could not be eluted from the column in contrast to GST-alone that could be purified by such method (Fig. 2C). We have developed a modified procedure that included additional step of solubilization of GST- toxin fusions in $0.5 \%$ sarcosyl that allowed us to isolate nearly pure proteins (Fig. 2D) that can be used for further testing of toxin activity.

A

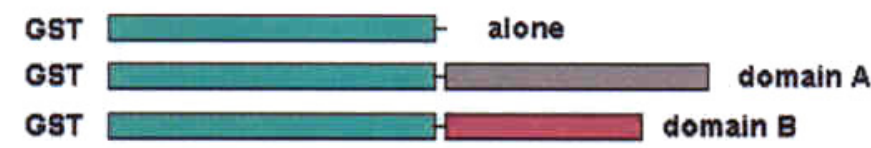

B

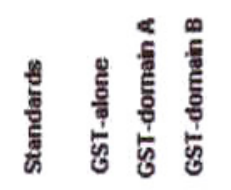

C

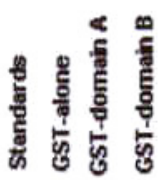

D
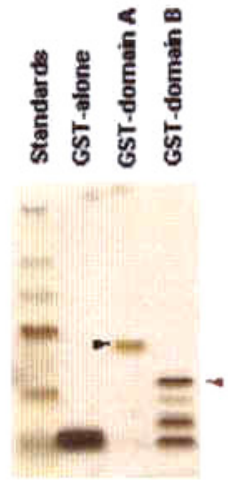
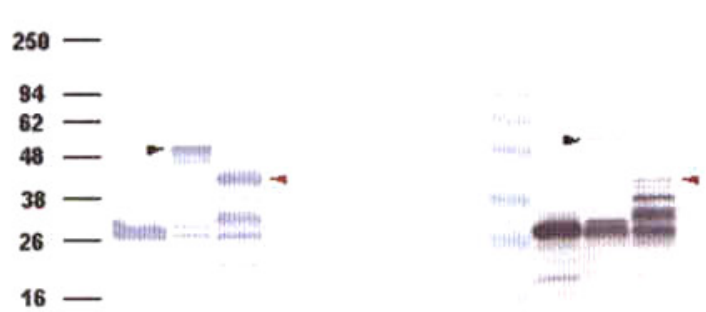

Fig. 2. Schematic representation of GST-fusion constructs (A). Immunoblots with anti-GST antibodies of protein samples containing GST recombinant proteins: whole-cells extracts (B) and peptides purified by standard affinity chromatography (C). Silver-stained gel showing purified GST-fusions by modified affinity chromatography (D).

The structural modeling of the putative EF of $Y$. pestis. The model building procedure that was applied to generate 3D models was performed using the methodology AS2TS homology-modeling protein structure prediction system (02-LW-003). The current model building process consisted of the following steps:

1. The set of preliminary sequence-structure alignments are generated using pairwise sequence alignment search methods (Smith-Waterman, FASTA, BLAST), and the multiple sequence alignment PSI-BLAST technique. A set of backbone models were then created automatically.

2 . The correctness of the alignment was verified by: 

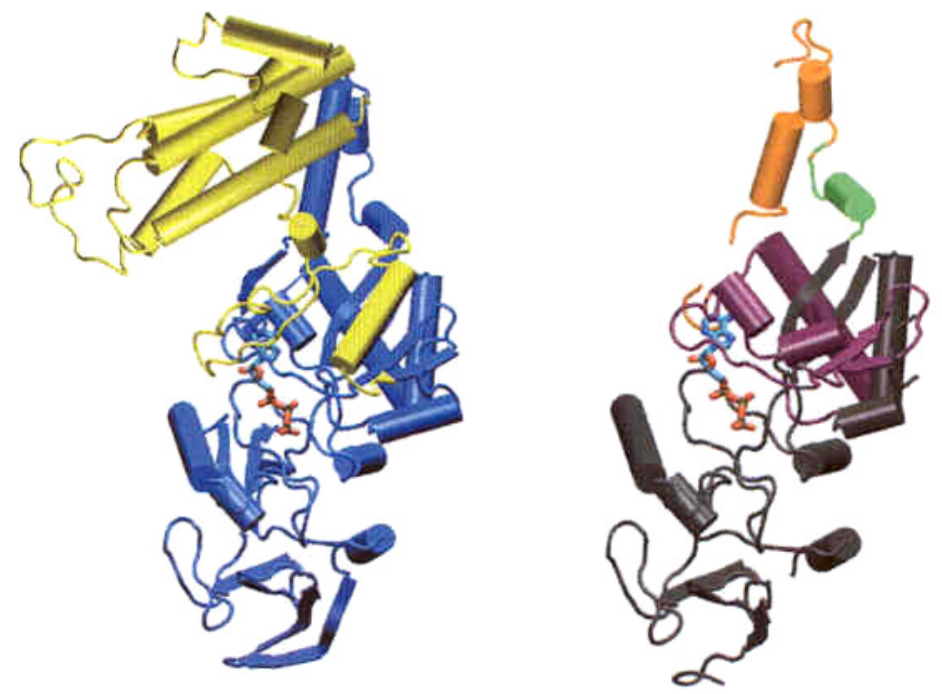

Fig. 3. Left: Anthrax EF toxin structure (CL Drum et al., Nature 2002). In blue is region homologous to $Y$. pestis putative toxin; in yellow is a non-homologous region, primarily responsible for binding calmodulin. Also shown is the bound ATP molecule, in a colored bonds representation. Right: Model of $Y$. pestis putative toxin. The dark grey and purple regions are two separate domains, both of which contact the ATP, and the green and orange regions are presumed to be flexible as in the EF toxin.

a) comparison and analysis of multiple sequence alignments and structure alignments between templates,

b) secondary structure prediction of templates and modeled protein,

c) detailed analysis and comparison of selected biologically important regions in templates and models,

d) structure comparison of all generated preliminary models.

3. The building process of the terminal regions, insertions, deletions, and loops were performed within our LGA program.

Using this procedure, we created a working model of the putative $Y$. pestis toxin from the published anthrax EF toxin structure (Fig. 3). There are two domains in the Y.pestis toxin, disjoined at the separation of the ORFs (green region). Both domains appear to be involved in ATP binding, with the domain in purple binding the purine and the domain in grey binding the phosphates. This model strongly supports our assertion that these ORFs may constitute a viable toxin in $Y$. pestis.

\section{Future Directions}

The results obtained encourage us to investigate the biochemical properties of this toxin as well as to determine the role of the toxin in $Y$. pestis pathogenicity by creating a mutant that is defective in producing this toxin. In addition, the mechanism of secretion of this toxin by the plague microbe as well as toxin delivery to its targeted host cell should be studied. The crucial step of such work would be the identification of the toxin receptor.

This work was performed under the auspices of the U.S. Department of Energy by the University of California, Lawrence Livermore National Laboratory under Contract No. W-7405-Eng-48. 